\title{
METHODOLOGICAL APPROACH TO THE RESEARCH OF ENERGY COGENERATION SYSTEMS OPERATIONAL RELIABILITY INDICATORS
}

\author{
A. DOMNIKOV, M. KHODOROVSKY \& L. DOMNIKOVA \\ Academic Department of Banking and Investment Management, Ural Federal University named after the \\ First President of Russia B.N. Yeltsin, Russia.
}

\begin{abstract}
The reliable operation of energy cogeneration systems as the most important component of large energy systems is essential for the successful development of a national economy. Not only technical, but also economic reliability aspects predetermine the complexity of studying the above-mentioned subjects and their interaction with other components of the economy and social sphere. As a result of calculations, an assessment of the level of reliability of the energy cogeneration systems of the Ural region was obtained. The obtained estimates made it possible to form a set of measures that will affect the increase in reliability of energy cogeneration systems and in the future will ensure the optimal allocation of resources to increase the competitiveness of energy generating companies. Also, the influence of energy cogeneration systems properties as technical and economic objects on the formation of the power generation reliability level of a large region has been assessed. Based on the results of the calculations, the reliability levels of the Urals energy cogeneration systems are determined and an analysis of their operational reliability is presented.

Keywords: centralized energy sources, competition, efficiency, mathematical economic models, power industry, reliability, risks, strategy, uncertainty.
\end{abstract}

\section{INTRODUCTION}

The reliable operation of energy cogeneration systems as the most important component of large energy systems is essential for the successful development of a national economy. Not only technical, but also economic reliability aspects predetermine the complexity of studying the above-mentioned subjects and their interaction with other components of the economy and social sphere in order to determine the best control actions to achieve an economic effect and to maintain a constant readiness of power systems to cope with operational threats arising in periods of economic and political crises, as well as at catastrophes and disasters.

Crisis processes in the Russian electric power industry have led to the development of two interconnected systems in power generation. The first system includes power generating capacities of large thermal, nuclear and hydraulic power plants, which mainly provide power balances in power systems, reliable operation of the country's power system and maintaining standard parameters of the quality of electric power in it. The second generation system belongs to the territorial level and forms the energy cogeneration system. Within the framework of this system, joint generation of electric and thermal energy is carried out at combined heat and power plants. At the same time, it differs in a lower level of concentration and centralization of energy production in comparison with the first, and also determines the structure of the regional energy system. The regional energy system is based on the cogeneration system, which is divided into [1-3]: (1) a centralized system, which mainly consists of cogeneration energy sources of the heating type, which are part of the territorial generating company; (2) a distributed system consisting of cogeneration energy sources of medium and low power located near the centers of energy loads, including serving individual groups of consumers (usually in remote areas of the region). With a rational combination, centralized 
and distributed systems can complement each other. This creates a rather flexible system of cogeneration of energy in the territory, which is a key link in the regional energy sector. This system of cogeneration of energy is able to reliably provide consumers with electrical and thermal energy, and successfully compete with energy sources performing separate generation of energy, due to the implementation of the competitive advantages of cogeneration [4].

When analyzing the reliability of energy cogeneration systems, an approach based on the graph theory is used, where the elements of the system (subsystems) and their interconnections are analyzed, and the connections between objects are manifested through output variables that characterize the states of the entire system $[5,6]$. These connections operate through the topology, modes, structure of the system, etc. In accordance with this approach, the more connections there are between the elements of the system, the higher the reliability of the system, and the loss of the reliability of the functioning of one element is compensated by others that are strongly related to this. This approach is used to analyze the effect of the properties of energy cogeneration systems that are part of the energy sector of the Ural region on the level of reliability.

Based on the above ideas, the formation of reliability indicators should be carried out in six blocks, which include: (1) The block of power systems adequacy; (2) the block of fuel supply systems adequacy; (3) the block of structural and secure electric power systems reliability; (4) the block of energy systems survivability; (5) the block of power companies main production assets reliability and efficiency; (6) the block of financial and economic reliability of fuel and energy supply [7-9].

As shown by a preliminary analysis, at present, most of the territories of the Urals have an insufficient or low level of reliability. There are no territories that have a high or acceptable level of reliability, noted for all indicators. At the same time, there is a high differentiation of the territories of the Ural region according to certain properties of reliability. In this regard, it is advisable to formalize the reliability analysis procedure in such a way that the calculation is carried out according to the integral indicators of energy cogeneration systems operation. The integral indicators are understood as indicators of energy cogeneration systems operation that characterize its work during the year. The advantage of this approach is the ability to compare the reliability levels of energy cogeneration systems in different territories of the region [10].

\section{METHODOLOGY FOR QUANTITATIVE EVALUATION OF THE INFLUENCE OF THE ENERGY COGENERATION SYSTEMS PROPERTIES AS TECHNICAL AND ECONOMIC OBJECTS ON THE POWER GENERATING INDUSTRY RELIABILITY LEVEL OF REGION}

Within the framework of the developed methodological approach to the analysis of energy cogeneration systems reliability, a method for reliability quantitative assessment is proposed. Calculations will show the need for measures in a particular area (block) of reliability. When analyzing individual territorial energy cogeneration systems, such approach may give a fairly comprehensive picture. The proposed reliability quantitative assessment method is aimed at studying the structural characteristics of energy cogeneration systems reliability, where the assessment of their reliability is based on the states of individual power generating facilities (power plants), which will provide an additional characteristic of their reliability.

Energy cogeneration systems are multi-level facilities. When studying such complex systems, it is highly justified to use a systematic approach. In accordance with the territorial hierarchy, the economy of territorial entities at regional level can be viewed as a large 
complex system. Based on the theory of systems, any multi-purpose system can be represented in the form of aggregates of its constituent subsystems and diverse connections between them [11]. Connections between objects are manifested through output variables that characterize the states of the entire system. In this case, the supply system is understood as a system of providing material, labor, financial and other resources [12,13]. For example, the Russian Federation is represented as its constituent seven federal districts; the district, in turn, consists of constituent entities of the Federation and so on, depending on the level of the territorial hierarchy. Thus, the Ural Federal District consists of six constituent entities of the Federation: The Sverdlovsk, the Kurgan, the Chelyabinsk and the Tyumen Oblasts, and within the Tyumen Oblast, there are two large constituent entities of the Federation - the Khanty-Mansi and Yamalo-Nenets Autonomous Okrugs.

In the economic system of territorial entities, a number of subsystems can be distinguished, corresponding to large life spheres: industrial, financial, social and environmental.

In the industrial sphere of life, the fuel and energy sector plays a special role due to its decisive impact on all other spheres. To this impact, the reliability and safety of energy cogeneration systems are of ultimate importance. Energy cogeneration systems reliability depends not only on the characteristics of its constituent subsystems (fuel supply, power supply, etc.), but also on the structure of the entire system. Moreover, the system reliability decreases as a result of its constituent subsystems disruption, that is, if the technical and economic structures of the subsystems are different and poorly coordinated [1-3].

Symbolically, the reliability of a multipurpose system may be represented by the following expression:

$$
H=\left\{\begin{array}{l}
x_{1 l o w} \leq x_{1} \leq x_{1 u p} \\
\hdashline x_{i l o w} \leq x_{i} \leq x_{i u p} \\
\hdashline x_{n l o w} \leq x_{n} \leq x_{n u p}
\end{array}\right.
$$

where $H$ is an event expressing the system property to perform the specified functions in the required volume in compliance with all established standards, $x_{i l o w}, x_{i \text { up }}$ are, respectively, the lower and upper limits of the system operation required result for a certain target (task), $n$ is the number of targets, $\boldsymbol{x}_{i}$ is an actual operational result for the $i$ - th target.

The informational content of system 1 is a separate task. The variables used are standardized in order to be comparable with one another. The standardized variables have a zero mathematical expected value and an occasional root-mean-square deviation. To study connections of individual subsystems, it is necessary to solve the taxonomy task, when the subsystems that make up the system are divided into classes, within which the connections are strong enough, and between the classes weak [5, 14]. To use fairly simple taxonomy algorithms, all parameters characterizing these multiple relationships, that is, indicative indicators, are represented as combinations of 0 and 1 . For simplicity, let each parameter be represented in binary form. Provided that

$$
x_{i b}^{n}=\left\{\begin{array}{c}
1, \text { if } x_{i}^{s} \geq x_{i t h r e s h o l d}^{s} \\
0 \text {-otherwise }
\end{array}\right.
$$


where $\boldsymbol{x}_{\text {ithreshold }}^{S}$ is the standardized threshold parameter value, which can be adopted on the basis of expert judgment. Determination of threshold levels is a separate task of discriminant analysis.

After compiling the table "objects-features" for each pair of lines, the coefficient of objects "proximity" (similarity) is calculated and the results are summarized in a square symmetric matrix.

Similarity is understood as a function $\boldsymbol{\rho}(\boldsymbol{j}, \boldsymbol{m})$, which takes real values when the description elements of objects $j$ and $m$ are substituted into it. The similarity means a certain "distance" between subsystems, which is a positive value, has the properties of symmetry and maximum similarity with itself, i.e.

$$
\rho(j, m)>0 ; \rho(j, m)=\rho(m, j) ; \rho(j, j)=\max \rho(j, m) .
$$

Thus, the greater the "distance" is, the greater is the similarity of objects, i.e. the connection between subsystems is closer.

When a symmetric matrix is obtained, then by means of a threshold transformation this matrix is transformed into a binary matrix, which is interpreted as a vertex incidence matrix. In the last graph, the apexes denote objects, and the edges - proximity relations between them, that is, connections between subsystems (objects).

It is known that the incidence matrix for any graph $G$ looks as follows:

$$
\boldsymbol{A}=\left\|\boldsymbol{a}_{j m}\right\|,
$$

where $a_{j m}=\left\{\begin{array}{c}1, \text { in the presence of links between vertices } j \text { and } m \text {. } \\ 0 \text {-otherwise. }\end{array}\right.$

For quantitative assessment of structural compactness, a parameter is introduced that reflects the "proximity" of elements to each other. The proximity of two objects $j$ and $m$ to each other will be determined using the Rogers-Tanimoto proximity criterion:

$$
s_{j m}=\frac{\varsigma_{j m}^{(I, I)}}{\varsigma_{j}^{(I)}+\varsigma_{m}^{(I)}-\varsigma_{j m}^{(I, I)}},
$$

where $\zeta_{j m}^{(I, I)}$ is the number of coinciding single features for both lines $j$ and $m$ of the "objects - features" table, when the features are presented in binary form $\zeta_{j}^{(I)}$, and $\zeta_{m}^{(I)}$ are the total number of single features in each line corresponding to objects $j$ and $m$.

After the threshold transformation of the "proximity" matrix (with the selected threshold), we obtain the graph adjacency matrix. For each pair of lines $j$ and $m$ of this matrix, we apply the Rogers-Tanimoto proximity criterion [5], [6].

The energy cogeneration systems reliability in this case can be assessed as the ratio between the connections in the "complete graph" and in the specific resulting graph with $J$ apexes, that is

$$
H=\frac{t}{t_{c g}}=\frac{2 t}{J(j-1)}
$$

where $t$ and $t_{c g}$ - respectively, the number of connections in the Graph and in "complete graph" $\left(\boldsymbol{t}_{c g}=J(J-1) / 2\right)$. 
The rank of an element (of energy cogeneration system of a separate territory) is of great importance in the study of energy cogeneration systems reliability. The rank of an element determines its significance in the sense of forming a synthetic indicator of the interconnection reliability and is defined by the number of connections of this element with the other.

The higher the rank of an element, the more strongly it is connected with other elements of the system and the more severe the consequences will be when its operation quality changes, that is, it greatly affects the reliability and should, first of all, be an object of control. Along with the graphic representation of the Graph, the rank of an object can be determined analytically from the following expression:

$$
\text { rank }=\frac{\sum_{m=1}^{J} \alpha_{j m}^{(k)}}{\sum_{j=1}^{j} \sum_{m=1}^{j} \alpha_{j m}^{(k)}},
$$

where $\boldsymbol{a}_{j m}^{(k)}$ - matrix element $\boldsymbol{A}^{k}, k=3 \ldots 4$. The sum of all ranks must be equal to one.

\section{QUANTITATIVE ASSESSMENT OF THE URAL ENERGY COGENERATION SYSTEMS RELIABILITY}

The above method of quantitative assessment is used to analyze how reliable are the Ural energy cogeneration systems. The calculations under this technique must provide the answers to the following questions:

1. What is the reliability level of the Urals cogeneration system as a whole?

2. What territorial energy cogeneration systems have the greatest impact on the reliability level of the energy cogeneration system in the Urals?

The Ural zone of energy cogeneration system includes nine territories: Bashkir $(B)$, Kirov $(K)$, Kurgan $\left(K^{\prime}\right)$, Orenburg $(O)$, Perm $(P)$, Sverdlovsk (S), Udmurt $(U)$, Chelyabinsk $(C)$ and Tyumen $(T)$.

It is obvious that the crisis phenomena in the territorial energy cogeneration systems will be reflected in different ways on the reliability of the entire energy cogeneration system in the Urals. The most developed energy cogeneration systems, which have power plants with a large total installed capacity, developed backbone networks and strong intersystem connections, will have a stronger impact on the reliability level of the Urals cogeneration system. These are, first of all, the Tyumen and the Sverdlovsk energy cogeneration systems. The Tyumen system is the most technically advanced one with lesser wearing of power plant equipment. In addition, the Tyumen Region possesses the richest gas producing fields in Russia, including associated gas, with power plants as the main consumers, which makes the issues of fuel supply less acute.

The huge spaces of the Tyumen region, combined with a small number of settlements, set the specifics of the Tyumen cogeneration system: extended high and ultra-high voltage power lines. The Tyumen cogeneration system has a length of $110 \mathrm{kV}$ and higher overhead transmission lines of more than $35,288 \mathrm{~km}$ (in single-circuit equivalent). As to the Sverdlovsk cogeneration system, the length of HV $110 \mathrm{kV}$ and higher lines was 12,505 km in 1999, which is almost three times less than in Tyumen. However, the installed power plants capacities of the Tyumen and the Sverdlovsk cogeneration systems are comparable (10421 and 8298 MW, respectively). Other cogeneration systems of the Urals have no similar indicators of production capacity. All of the above allows us to conclude that these two systems 
determine the reliability level of the Ural energy cogeneration system to the greatest extent. Therefore, we will attribute them to the first group of importance.

The second group includes the Bashkir, the Orenburg, the Perm and the Chelyabinsk cogeneration systems. These are the systems with developed structure, large total capacity of power plants, but their production potential is insufficient to have a decisive influence on the reliability level of the entire energy cogeneration system of the Urals. The length of power transmission lines and the total power plants installed capacity indicators are more than 1.5 times lower than those for the Sverdlovsk cogeneration system, not to mention Tyumen. In other words, the shortfall in electricity production in one of these energy cogeneration systems can be compensated for by others, provided that they do not experience any such difficulties. In this case, the power reserve of the Urals cogeneration system is sufficient to overcome emergencies associated with the disconnection of consumers.

The impact on the situation in the Ural energy cogeneration system will increase if the state of reliability of these systems is close to each other. For example, heavy wearing of the equipment of energy cogeneration systems referred to the second group, and, as a consequence, a decrease in the reliability of its operation, can lead to power shortage at the level of the Ural energy cogeneration system. The proposed quantitative assessment method allows identifying threats affecting several cogeneration systems. Their combined effect is more dangerous as related to the Urals cogeneration system reliability than similar threats coming from one cogeneration system. Therefore, identifying such situations is an important task.

A database containing a set of 23 indicators characterizing the operation of energy cogeneration systems operating in the Urals for the period from 2009 to 2020 that were used in the calculations are shown in Table 1.

The third group includes the Kirov, the Kurgan and the Udmurt cogeneration systems. These are clearly deficient systems. Their net power flow is negative (energy deficit) and is on the level of their own energy production, and in the Kurgan energy cogeneration system, the net power flow 4.5 times exceeds their own electricity production. The absolute values of electricity consumption in these cogeneration systems are 7-12 times less than in Tyumen. Their great dependence on external electricity supplies makes their operation reliability dependent on other cogeneration systems operating in the Urals. Therefore, no crisis in these energy cogeneration systems, even in several of them simultaneously, can significantly affect the operation reliability of the Urals energy cogeneration system.

In the calculations, the integral indicators of the Urals energy cogeneration systems operation for the period from 2009 to 2020 were used. The database is a collection of 18 indicators. If we identify the indicators used in the analysis according to their role in the problem solved, then these include unmanaged, criterial and controlled indicators. They are also internal indicators in relation to the problem being solved, but by nature they are, first of all, technical and, partially, economic ones.

The calculations made it possible to trace the dynamics of changes in the reliability level for the Ural energy cogeneration system as a whole and the situations proximity between individual energy cogeneration systems for more than a decade, which cannot be called homogeneous from the point of view of the conditions of power systems operation. It should be noted that in each year the reliability level of energy cogeneration systems is different. It is determined by the levels of operational reliability and by similarity of situations between energy cogeneration systems. The threats to the reliability that are of interest to us each time (year) can come from different energy cogeneration systems. When using the above methodology, the threats are determined based on cumulative, most general threats to the operational 
Table 1: Calculations results of the reliability level of the Urals cogeneration systems.

\section{Indicator block Indicators}

1. The block of power systems adequacy
1.1. The share of own sources of electric energy in the energy balance of the territory.

1.2. The ratio of available power plants capacity to the maximum consumers power load.

1.3. The ratio of the sum of the available power plants capacity and the throughput capacity of interconnection lines with neighboring ones to the maximum power load of consumers.

2. The block of fuel supply systems adequacy

3. The block of structural and se2.1. The share of own sources in the balance of boiler and furnace fuels. 2.2. Share of own sources in the balance of motor fuel.

2.3. Share of target figure fulfillment for the accumulation of coal fuel by power generating companies.

2.4. The share of target figure fulfillment for the accumulation of heavy fuel oil by power generating companies.

cure electric power 3.2. The territory power plants reserve to consumers maximum electrisystems reliability cal load ratio.

3.3. Availability factor of the territory heat power plants generating equipment.

3.4. The territory maximum consumers limiting power to the maximum consumers electrical load ratio.

4. The block of energy systems survivability

5. The block of power companies main production assets reliability and efficiency.

6. The block of financial and economic reliability of fuel and energy supply.
4.1. The share of the territory power plants operating on the dominant resource in the territory power system electrical energy balance.

4.2. The installed capacity share of the largest power plant.

4.3. The level of securing the demand for heat sources capacity in the conditions of a sharply increased demand for them on the territory.

5.1. Depreciation of power generating companies fixed assets.

5.2. Depreciation degree of the fuel industry enterprises basic production assets.

5.3. Depreciation degree of main fixed assets in the heat power industry of the territory.

5.4. The share of commissioning the installed capacity and technical re-equipment of power plants in the territory over a five-year period.

6.1. The ratio of the excess of accounts payable of power generating companies over accounts receivable to their annual production volume.

6.2. The ratio of the excess of accounts payable of enterprises in the fuel industry over accounts receivable to their annual output.

6.3. The ratio of overdue accounts payable of electric power enterprises to their annual output.

6.4. The ratio of overdue accounts payable of fuel industry enterprises to their annual output.

6.5. The ratio of the debt of power generating companies for the supplied fuel to their annual production volume. 
reliability of individual cogeneration systems in the Urals. Moreover, they are all divided into groups (as described above), and cumulative threats should be determined based on their significance.

An important issue is the adoption of a threshold level at determining similar situations in energy cogeneration systems. Moving from a continuous scale to a binary one, it is necessary to decide what level of objects (systems) "similarity" shall be considered sufficient in order to think that individual energy cogeneration systems have the same effect on the overall operational reliability. The threshold level is to be chosen on the basis of empirical data, remembering that the higher the threshold is, the more stringent requirements are imposed on the degree of "similarity" (common points) of the objects. Accordingly, such objects connected in a graph can to a greater extent affect the level of reliability of the Ural energy cogeneration system.

The initial information was reduced to a binary form using equation (2). As a threshold level, the mathematical expectation is taken $-t(x)$ of the class corresponding to the class of pre-crisis situations [6].

After constructing the Rogers-Tanimoto "proximity" matrix, introducing a proximity threshold of 0.4, graphs are constructed that clearly represent the state of reliability of the operation of the Ural energy cogeneration system in the period from 2009 to 2020. A fragment of the graphs of the quantitative reliability of the Ural energy cogeneration system for 2010, 2011, 2019, 2020 is shown in Figure 1.

Energy cogeneration systems in Figure 1 are indicated by the first letters of their names (for example, the Kurgan cogeneration system is designated as $K^{\prime}$ ). In Figure 1, the dotted line marks the links of unclassified objects, i.e. when using the applied mathematical apparatus, it is impossible to unambiguously assert to which one of the two polar classes normal (n) or crisis (k) the object (observation) belongs. This situation can be interpreted as finding an object in a transitional state. The calculation results are presented in Table 2 and in Figure 2.

The graph of calculated reliability values presented in Figure 2 shows that the greatest value of $H$ was recorded in 2009. In the period from 2010 to 2012, there was some gradual decrease in the reliability level from 0.786 to 0.750 . From 2012 to 2015 , there was a significant reliability indicator decrease. The minimum value was recorded in $2016-0.194$. These results show that in recent years the Ural energy cogeneration system, like most of the systems included in it, has a low level of operational reliability. In 2019, the increase in the numerical value $H$ can only be explained by the fact that many objects have weak connections that only slightly exceed the threshold values (dotted lines at Figure 1), moreover, by the results of 2020, the reliability level has decreased again: a significant number of the objects is close to, but their values are already somewhat below the thresholds.

For individual energy cogeneration systems, the ranks characterizing the importance of the reliability of entire Urals energy cogeneration system are calculated. The results are presented in table. 3 .

Table 3 shows that as the reliability decreases (the number of connections in the graph decreases), the spread in the rank values grows. The cost of communication goes up. The only situation when it is impossible to determine the ranks is a graph without connections, and the quantitative assessment of interconnection reliability calculated using this method, is equal to zero.

The disadvantage of this calculation is that all objects (energy cogeneration systems) in the model are assumed to be equivalent. The model does not include the indicators absolute values. The non-use of absolute indicators is explained by the incomparability of objects with each other in terms of absolute indicators. Therefore, at the beginning of this paragraph, an 


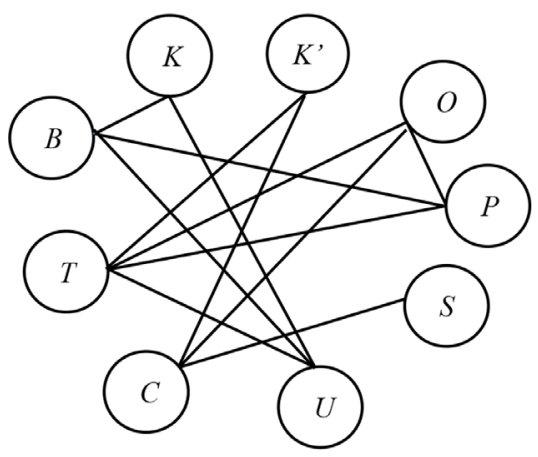

a) $H=0.25(2020)$

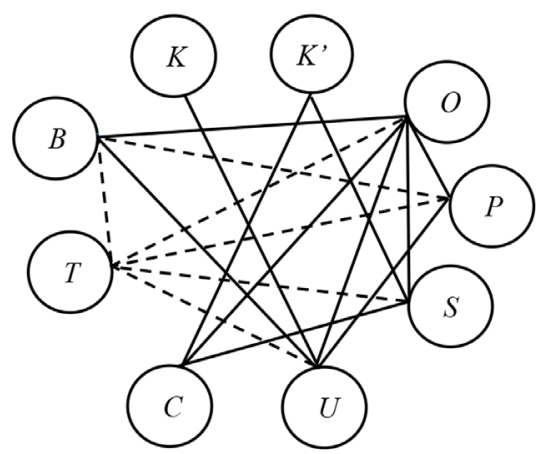

b) $H=0.44$ (2019)

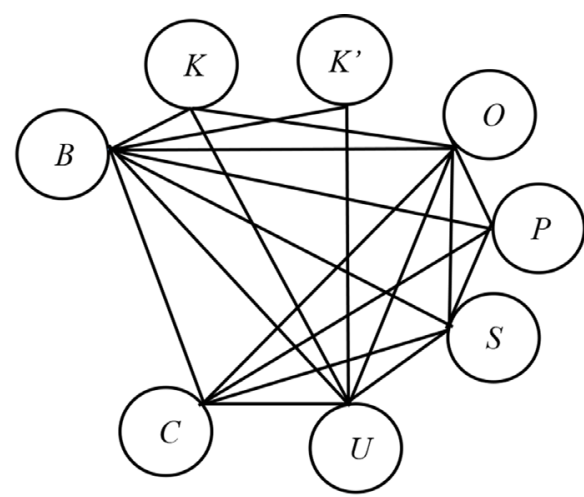

c) $H=0.78(2010)$

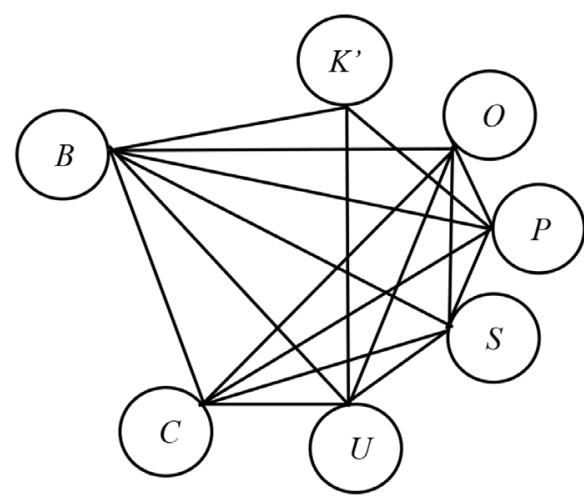

d) $H=0.81$ (2009)

Figure 1: Graphs of the quantitative reliability of the Urals cogeneration system.

analysis of power systems is carried out in terms of absolute values characterizing the production potential of these power systems.

Three groups of systems were identified according to the level of their production potential. Taking into account the above, it is possible to introduce a generalized assessment of the object, taking into account its potential and rank and determined through their product. The higher the potential of an object, the higher is its weight. So the objects of the first group (the Tyumen and the Sverdlovsk energy cogeneration systems) will be assigned a weight equal to three, the objects belonging to the second group (the Bashkir, the Orenburg, the Perm and the Chelyabinsk energy cogeneration systems) - equal to two, and the third group objects (the Kirov, the Kurgan and the Udmurt cogeneration systems) - one. The weights are introduced into the calculation when the matrix $A$ is obtained by multiplying the corresponding line by the weight, and then normalized so that the sum of the ranks for one year is equal to one (Table 4).

As a result, the ranks will be adjusted depending on the production potential of the cogeneration systems. Comparing the ranks values calculated in two ways, one can see an increase in the ranks values of more powerful energy cogeneration systems in Table. 4 as compared with the values in Table. 3 . 
Table 2: Calculations results of the reliability level of the Urals cogeneration systems.

\begin{tabular}{llll}
\hline Place by level & Year & Numerical value $H$ & Note \\
\hline 10 & 2020 & 0.250 & \\
6 & 2019 & 0.444 & two objects in transition \\
9 & 2018 & 0.286 & two objects in transition \\
8 & 2017 & 0.306 & \\
12 & 2016 & 0.194 & \\
11 & 2015 & 0.214 & \\
7 & 2014 & 0.357 & \\
5 & 2013 & 0.500 & \\
$3-4$ & 2012 & 0.750 & \\
$3-4$ & 2011 & 0.750 & \\
2 & 2010 & 0.786 & \\
1 & 2009 & 0.810 & \\
\hline
\end{tabular}

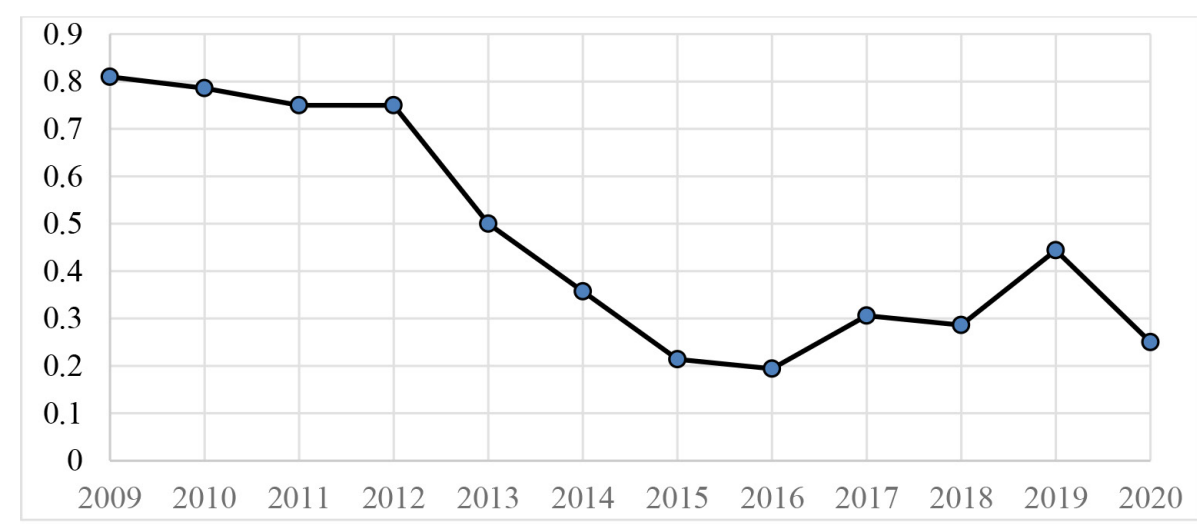

Figure 2: Graph of reliability indicators values for the Urals cogeneration system in the period 2009-2020.

Power system ranks are an additional tool for analyzing the cogeneration systems reliability. The essence of the quantitative assessment method is the reliability assessment based on the analysis of subsystems with the calculation of the numerical value of reliability. The model takes into account the connections between individual measures, objects and external objects implicitly. The attractiveness of the quantitative reliability assessment method lies, first of all, in the visibility of the results. Another advantage is the use of the systematic approach idea that the cogeneration system reliability as a whole depends on the reliability of its components.

\section{ASSESSMENT OF THE STATE AND RANKING OF THE URAL ENERGY COGENERATION SYSTEMS}

The territorial energy cogeneration systems identified in the result of the held reliability analysis and the obtained quantitative assessment of the overall reliability level of energy cogeneration system in the Urals made it possible to determine the state and the position 
Table 3: Calculated ranks of energy cogeneration systems for the period 2009-2020.

\begin{tabular}{lllllllllllll}
\hline $\begin{array}{l}\text { Energy } \\
\text { cogeneration } \\
\text { system }\end{array}$ & $\mathbf{2 0 2 0}$ & $\mathbf{2 0 1 9}$ & $\mathbf{2 0 1 8}$ & $\mathbf{2 0 1 7}$ & $\mathbf{2 0 1 6}$ & $\mathbf{2 0 1 5}$ & $\mathbf{2 0 1 4}$ & $\mathbf{2 0 1 3}$ & $\mathbf{2 0 1 2}$ & $\mathbf{2 0 1 1}$ & $\mathbf{2 0 1 0}$ & $\mathbf{2 0 0 9}$ \\
\hline Bashkir & 0.185 & 0.161 & 0.207 & 0.131 & 0.049 & 0.206 & 0.214 & 0.177 & 0.144 & 0.146 & 0.139 & 0.167 \\
Kirov & 0.139 & 0.025 & 0.043 & 0.023 & 0.049 & 0.088 & 0.019 & 0.121 & 0.125 & 0.146 & 0.139 & - \\
Kurgan & 0 & 0 & 0.076 & 0.045 & 0 & 0.029 & 0.057 & 0.032 & 0.025 & 0 & 0.023 & 0.092 \\
Orenburg & 0.093 & 0.178 & 0.207 & 0.193 & 0.293 & 0.206 & 0.214 & 0.196 & 0.144 & 0.146 & 0.139 & 0.169 \\
Perm & 0.13 & 0.135 & 0.207 & 0.136 & 0.146 & 0.029 & 0.176 & 0.123 & 0.144 & 0.146 & 0.139 & 0.151 \\
Sverdlovsk & 0.028 & 0.16 & 0.109 & 0.148 & 0 & 0.176 & 0.176 & 0.142 & 0.125 & 0.146 & 0.139 & 0.151 \\
Udmurt & 0.185 & 0.108 & 0.109 & 0.057 & 0.098 & 0.176 & 0.143 & 0.129 & 0.149 & 0.125 & 0.143 & 0.145 \\
Chelyabinsk & 0.065 & 0.072 & 0.043 & 0.114 & 0.122 & 0.088 & 0 & 0.08 & 0.144 & 0.146 & 0.139 & 0.126 \\
Tyumen & 0.176 & 0.161 & - & 0.153 & 0.244 & - & - & - & - & - & - & - \\
\hline
\end{tabular}

Table 4: Ranks of cogeneration systems based on their potential for the period 2009-2020.

\begin{tabular}{lllllllllllll}
\hline $\begin{array}{l}\text { Energy } \\
\text { cogeneration } \\
\text { system }\end{array}$ & $\mathbf{2 0 2 0}$ & $\mathbf{2 0 1 9}$ & $\mathbf{2 0 1 8}$ & $\mathbf{2 0 1 7}$ & $\mathbf{2 0 1 6}$ & $\mathbf{2 0 1 5}$ & $\mathbf{2 0 1 4}$ & $\mathbf{2 0 1 3}$ & $\mathbf{2 0 1 2}$ & $\mathbf{2 0 1 1}$ & $\mathbf{2 0 1 0}$ & $\mathbf{2 0 0 9}$ \\
\hline Bashkir & 0.197 & 0.147 & 0.220 & 0.120 & 0.047 & 0.219 & 0.219 & 0.190 & 0.158 & 0.156 & 0.152 & 0.174 \\
Kirov & 0.074 & 0.011 & 0.023 & 0.011 & 0.023 & 0.047 & 0.010 & 0.065 & 0.068 & 0.078 & 0.076 & - \\
Kurgan & 0 & 0 & 0.040 & 0.021 & 0 & 0.015 & 0.029 & 0.017 & 0.014 & 0 & 0.013 & 0.048 \\
Orenburg & 0.099 & 0.163 & 0.220 & 0.177 & 0.279 & 0.219 & 0.219 & 0.211 & 0.158 & 0.156 & 0.152 & 0.176 \\
Perm & 0.138 & 0.123 & 0.220 & 0.125 & 0.139 & 0.031 & 0.180 & 0.132 & 0.158 & 0.156 & 0.152 & 0.158 \\
Sverdlovsk & 0.045 & 0.219 & 0.174 & 0.204 & 0.000 & 0.281 & 0.270 & 0.229 & 0.205 & 0.233 & 0.227 & 0.236 \\
Udmurt & 0.098 & 0.049 & 0.058 & 0.026 & 0.047 & 0.094 & 0.073 & 0.069 & 0.082 & 0.067 & 0.078 & 0.076 \\
Chelyabinsk & 0.069 & 0.066 & 0.046 & 0.105 & 0.116 & 0.094 & 0 & 0.086 & 0.158 & 0.156 & 0.152 & 0.132 \\
Tyumen & 0.281 & 0.221 & - & 0.211 & 0.349 & - & - & - & - & - & - & - \\
\hline
\end{tabular}

(significance) of territorial energy cogeneration systems in the regional power production industry. Based on these results, it is possible to propose the measures to normalize the situation in those systems where the situation is critical.

The proposed measures for improvement of the reliability levels will be presented in the form of a general list, and the need for their application in individual cogeneration systems will be noted in the description of each system. The proposed activities are based on the processing of available information and taking into account the opinions of experts - heads of energy companies. Therefore, a full range of measures for them should be developed using additional information about the facilities (indicators of technical, financial, environmental and other areas). Thus, the measures to ensure the improvement (stabilization) of power systems include:

1. Improving the technological readiness level of power plant equipment.

2. Improving the electricity generation process efficiency, including technical and organizational measures. 
3. Improving the electricity distribution process efficiency, including technical and organizational measures.

4. Measures to reduce the number of disorders in the operation of power plants.

5. Reconstruction and modernization of the main equipment of power plants.

6. Construction of new power lines, cable lines, and heating networks.

7. Construction or re-equipment of power plants with highly efficient combined cycle gas and gas turbine plants.

8. Organizational and technical measures in the field of energy saving.

Measures 5 and 8 are common for all cogeneration systems, as they reflect common problems in the regional energy sector. We will rank the energy cogeneration systems, according to the aggregate assessment, by their states in order of deterioration of the situation and put down the measures proposed for them:

1. The Tyumen cogeneration system is in the most favourable position: it is in the best position in terms of overall impact on the operational reliability. In this regard, it is important for it to maintain and develop its potential, both for its own purposes and for the purposes of the Ural energy cogeneration system. Activity 4 is proposed.

2. The Bashkir energy cogeneration system is in a better position than the Sverdlovsk one. With approximately the same reliability situation during 2020, it has a large number of "connections" with other systems. Therefore, it is more flexible and resistant to any negative changes in the situation. The following measures are proposed: 2,3 .

3. The large industrial potential of the Sverdlovsk cogeneration system presents some special requirements to the conditions of electric power supply. Lately, as noted above, there has been power deficit in on-peak conditions. In this regard, it is necessary to increase the level of equipment technical readiness. Besides, the efforts are needed to optimize the electricity production and distribution processes, and not only of security, but also of organizational nature (for example, structural changes and new management methods). Due to the fact it's not similar to other power systems, it will have to rely mainly on its own resources and reserves. To improve the situation, the following measures are proposed: 1,2 and 4.

4. In spite of being in the critical zone, the Orenburg energy cogeneration system showed at the quantitative reliability assessment that it is well connected with other systems. The crisis recorded for this system reflects rather the situation in economy and industry of the territory than in the energy sector. Therefore, it is necessary to timely update the main production assets and introduce effective electricity production and distribution technologies in order to increase the level of competitiveness on the electric and heat energy market. Suggested measures: 2 and 3.

5. A noticeable increase in electricity per capita consumption in the Perm region leads to the need of not only energy cogeneration system optimization, but also to strengthening of its structure. The increased load on the system should be compensated for by increasing the operating capacities at the power plants. The following measures are proposed: 3 and 7.

6. The critical character of the Kurgan cogeneration system is determined by a rather weak territorial energy sector. However, its geographic proximity and connectivity with powerful and redundant cogeneration systems raises the overall level of its reliability. Suggested measures: $1,2,3,5$ or 6,7 . 
7. The performance indicators of the Udmurt cogeneration system are most favorable. Though the system is critical, the situation over the past 10 years has not changed significantly as in other energy cogeneration systems in the Urals. To increase the energy independence, the following measures are proposed: $1,3,5$ or 6,8 .

8. The situation with the Kirov energy cogeneration system is in many respects similar to that of the Udmurt system, therefore, the proposed measures do not differ for this energy system either.

9. The Chelyabinsk power system is classified as one of the most unfavorable cogeneration systems in the Urals. But at present, the low efficiency of electrical and thermal energy production process makes its power plants uncompetitive compared to isolated generating plants located in the Tyumen and in the Sverdlovsk regions. Therefore, it is necessary to put efforts to eliminating these shortcomings. To improve the condition, measures 1 , 5 or 7 are proposed.

\section{CONCLUSIONS}

As a result of the study, corrected ranks were obtained depending on the production potential of energy cogeneration systems, the value of which showed how strongly the energy cogeneration system of a separate territory of the Urals is connected with other elements of the cogeneration system of the entire Ural region.

Using the proposed methodological approach, the calculated ranks make it possible to identify the most problematic from the point of view of reliability of the cogeneration system. This allows us to study the issue of their mutual influence on reliability and assess the possibilities of power generating companies for mutual cooperation to improve their own reliability.

In further studies, it is planned to study the problem of the impact of the proposed measures to improve the reliability of the cogeneration systems of the Ural region on the competitiveness of power generating companies engaged in the combined production of electric and thermal energy. The information obtained will be useful for the management of power generating companies in the process of making decisions to optimize resources and use competitive advantages by increasing the level of reliability.

\section{ACKNOWLEDGEMENT}

The work was supported by the Russian Foundation for Basic Research (RFBR), Contract No. 20-010-00886 and Act 211 of the Government of the Russian Federation, Contract No. 02. A03.21.0006.

\section{REFERENCES}

[1] Domnikov A., Khodorovsky, M. \& Domnikova L., Improving the system of diagnostics of energy companies' competitiveness. European Proceedings of Social and Behavioural Sciences EpSBS, 105, pp. 498-507, 2020. https://doi.org/10.15405/epsbs.2021.04.54

[2] Domnikov, A., Antipova, E. \& Domnikova, L., Diagnostics of competitiveness of power-generating companies. WIT Transactions on Ecology and the Environment, 222, pp. 27-33, 2019. https://doi.org/10.2495/EQ180031

[3] Domnikov, A., Antipova, E. \& Domnikova, L., Evaluation of economic risks for power-generating companies. WIT Transactions on Engineering Sciences, 121, pp. 125-133, 2018. https://doi.org/10.2495/RISK180111 
[4] Mehigan, L., A review of the role of distributed generation (DG) in future electricity systems. Energy, 163, pp. 822-836, 2018. https://doi.org/10.1016/j.energy.2018.08.022

[5] Roberts, F. \& Tesman, D., Applied Combinatorics, Chapman \& Hall/CRC: New York, 2009.

[6] Wilson, R.J., Introduction to Graph Theory, Pearson Education Limited: Edinburgh, 2010.

[7] Butler, C., Parkhill, K. \& Luzecka, P., Rethinking energy demand governance: Exploring impact beyond energy policy. Technological Energy Research \& Social Science, 36, pp. 70-78. 2018. https://doi.org/10.1016/j.erss.2017.11.011

[8] Goldbach, K., Rotaru, A., Reichert, S., Stiff, G. \& Gölz, S., Which digital energy services improve energy efficiency? A multi-criteria investigation with European experts. Energy Policy, 115, pp. 239-248, 2018. https://doi.org/10.1016/j.enpol.2017.12.036

[9] Lombardi, P. \& Schwabe, F., Sharing economy as a new business model for energy storage systems. Applied Energy, 188, pp. 485-496, 2017. https://doi.org/10.1016/j. apenergy.2016.12.016

[10] McInerney, C. \& Bunn, D., Expansion of the investor base for the energy transition. Energy Policy, 129, pp. 1240-1244, 2019. https://doi.org/10.1016/j.enpol.2019.03.035

[11] Morley, J., Widdicks, K. \& Hazas, M., Digitalisation, energy and data demand: The impact of Internet traffic on overall and peak electricity consumption. Energy Research \& Social Science, 38, pp. 128-137, 2018. https://doi.org/10.1016/j.erss.2018.01.018

[12] Scholten, D. \& Künneke, R., Towards the comprehensive design of energy infrastructures. Sustainability, 8(12), pp. 1291-1295, 2016. https://doi.org/10.3390/su8121291

[13] Zhang, C. \& Yang, J., Economic benefits assessments of 'coal-to-electricity' project in rural residents heating based on life cycle cost. Journal of Cleaner Production, 213, pp. 217-224, 2019. https://doi.org/10.1016/j.jclepro.2018.12.077

[14] Lance, G.N. \& Williams, W.T., A general theory of classificatory sorting strategies. 1. Hierarchical systems. The Computer Journal, 9(4), pp. 373-380, 1967. 